\title{
Sleep insufficiency and incident diabetes mellitus among indigenous and minority populations in Greece
}

Anestis Matziridis ${ }^{1}$ Dimitrios Tsiptsios ${ }^{2 *}$ Apostolos Manolis ${ }^{1}$ Andreas Ouranidis ${ }^{3}$ Andreas S Triantafyllis ${ }^{4}$ Konstantinos Tsamakis ${ }^{5}$ Aspasia Serdari ${ }^{6}$ Eleni Leontidou Aikaterini Terzoudi ${ }^{7}$ Elena Dragioti ${ }^{8}$ Paschalis Steiropoulos 9 Gregory Tripsianis ${ }^{1}$
${ }^{1}$ Democritus University of Thrace, Laboratory of Medical Statistics Alexandroupolis - Thrace - Greece. ${ }^{2}$ South Tyneside \& Sunderland NHS Foundation Trust, Department of Clinical Neurophysiology - Sunderland - Tyne \& Wear - United Kingdom.

${ }^{3}$ Aristotle University of Thessaloniki, Department of Chemical Engineering Thessaloniki - Central Macedonia - Greece. ${ }^{4}$ Askepeion Hospital, Department of Cardiology - Athens Greece.

${ }^{5}$ King's College, Institute of Psychiatry, Psychology and Neuroscience - London United Kingdom.

${ }^{6}$ Democritus University of Thrace, Department of Child and Adolescent Psychiatry - Alexandroupolis - Thrace - Greece.

${ }^{7}$ Democritus University of Thrace, Neurology Department - Alexandroupolis - Thrace - Greece.

${ }^{8}$ Linköping University, Department of Health, Medicine and Caring Sciences Linköping - Linköping - Sweden.

${ }^{9}$ Democritus University of Thrace, Department of Pneumonology Alexandroupolis - Thrace - Greece.

*Corresponding author: Dimitrios Tsiptsios tsiptsios.dimitrios@yahoo.gr / tsiptsios. dimitrios@gmail.com

Received: October 14, 2020;

Accepted: December 8, 2020.

\begin{abstract}
Objective: To investigate the potential association between sleep pathology and diabetes mellitus (DM) using self-reported questionnaires. Material and Methods: 957 adults aged between 19 and 86 years old were enrolled in this cross-sectional study. Multistage stratified cluster sampling was used and subjects were classified into three groups [short $(<6 \mathrm{~h})$, normal $(6-8 \mathrm{~h})$ and long $(>8 \mathrm{~h})$ sleep duration]. Individuals were classified as diabetics if they responded positively to the questions: "Have you ever been told that you are diabetic or have high blood sugar by a health professional?" or "Are you on antidiabetic medication?". Sleep quality, utilizing Epworth sleepiness scale, Athens insomnia scale, Pittsburgh sleep quality index and Berlin questionnaire, was also examined. Results: DM prevalence was higher among expatriated and Muslim Greeks (23.1\% and 18.7\%, respectively) compared to indigenous Greek Christians (4.4\%). DM prevalence was significantly associated with short sleep duration $(\mathrm{aOR}=2.82, \mathrm{p}<0.001)$, excessive daytime sleepiness $(\mathrm{aOR}=2.09, \mathrm{p}=0.019)$ and poor sleep quality $(\mathrm{aOR}=2.56, \mathrm{p}<0.001)$, while its relation with insomnia $(\mathrm{aOR}=1.63, \mathrm{p}=0.065)$ and risk for obstructive sleep apnea $(\mathrm{aOR}=1.53, \mathrm{p}=0.080)$ were of marginal statistical significance. Conclusion: This study indicates an association between sleep quantity, quality and DM and supports early pharmacological and cognitive behavioral interventions on sleep disturbances in order to reduce the burden of DM with increased focus on minority population needs.
\end{abstract}

Keywords: Sleep Duration; Diabetes Mellitus; Sleep Quality; Insomnia. 


\section{INTRODUCTION}

Sleep is perceived as a complex dynamic process regulated by homeostatic and circadian effects. The iterated architecture is orchestrated by discrete hormonal changes, pertaining to significant glucose level and metabolism responses ${ }^{1}$. Habitual short sleep duration is linked to various morbidities, i.e., cardiometabolic abnormalities, stress, and obesity ${ }^{2}$, thus posing an unmet societal challenge ${ }^{3}$ prioritized for urgent health action plans ${ }^{4}$.

Diabetes mellitus (DM) is another prevalent lifelong disease characterized by elevated systemic glucose levels, owing to autoimmune destruction of $\beta$ cells of the endocrine pancreas in case of type $1 \mathrm{DM}$ (T1DM) or metabolic dysfunction and inflammation leading to insufficient pancreatic production of insulin and inefficient cellular absorption of glucose in case of type 2 DM (T2DM) 5 . According to WHO report of 2020, 422 million people worldwide currently suffer from DM, particularly in low and middle-income regions ${ }^{6}$.

Based on existing literature sleep disorders are more prevalent amongst subjects suffering from DM when compared to healthy populations? ${ }^{7}$. In case of DM sleep disorders may be attributed to variable factors, such as peripheral neuropathy, restless limb syndrome, abrupt glucose level changes fostering either hyper - or hypoglycemic disorders, sleep apnea, and nocturia ${ }^{8}$. Conversely, diabetic individuals present increased risk of depression and co-morbidity development, which affect critically the quality and duration of their sleep. Neurotransmitter, neurobehavioral and autonomic impact, adversely affect endocrine functions fostering sleep disorders?. Consequently, it is considered important to simultaneously study variables related to DM and sleep disturbance.

Since there exists no golden standard of human habitual sleep duration measurement, various methodologies, i.e., sleep diary, actigraphy and survey of modal or average sleep calculation have been implemented for such evaluations. Among them, selfreported questionnaires consist a valuable enabling tool to assess sleep disturbances ${ }^{10}$, aid insomnia diagnosis, and investigate various parameters, thus providing researchers with the opportunity to extrapolate the results in large population samples ${ }^{11,12}$, as in case of DM patient cohorts ${ }^{13,14}$.

In recently published cross-sectional studies, our research team utilizing self-reported questionnaires exhibited that short sleep duration and poor sleep quality are associated with increased prevalence of anxiety ${ }^{15}$ and depression ${ }^{16}$ in the primary care setting in Greece. In this paper, we aim to reveal possible correlations between sleep quantity and quality and DM, studying a regional representative Greek population cohort and taking into account several socio-demographic characteristics, lifestyle habits and health related characteristics of the participants.

\section{MATERIAL AND METHODS}

\section{Study sample and research design}

The study population in this cross-sectional study consisted of 957 participants, 439 (45.9\%) males and 518
$(54.1 \%)$ females, with a mean age of $49.62 \pm 14.79$ years (range, 19-86 years; median age, 50 years). The research design of this study is reported in Serdari et al. (2020) ${ }^{15}$.

\section{Ethics}

All procedures performed in the study were in accordance with the ethical standards of the Democritus University Ethics Committee, which approved its conduct, and with the standards of the Helsinki declaration (1964) and its later amendments. Informed consent was obtained from all participants of the study.

\section{Covariates}

A structured questionnaire was used to collect: a. standard socio-demographic characteristics (gender, age, place of residence, education level, marital, cultural, and employment status); b. lifestyle and dietary habits (smoking status, alcohol consumption, daily coffee consumption, caffeine consumption in the evening, adherence to the Mediterranean $\operatorname{diet}^{17}$, time watching TV or using a computer before bedtime, physical activity, and nap during the day); and c. health related characteristics (subjective general health status, body mass index, chronic disease morbidity, depression ${ }^{18}$ and anxiety symptoms ${ }^{19}$, and use of sleep medication) of the participants (Appendix).

\section{Measures of sleep}

Participants provided information on their nighttime sleep by answering the following sleep questions of the questionnaire: "At what time do you normally go to bed?", "At what time do you normally get up?" and "On average, how many hours do you sleep per day?" (Appendix). Responses were obtained for an average weekday and weekend day over the previous month. Time in bed was calculated as the difference between bedtime and rise time. As a proxy of the overall time in bed or sleep duration on a weekly basis, weighted mean measures were calculated using the following formulas: weighted time in bed $=5 / 7 *$ (time in bed on a weekday) + $2 / 7 *$ (time in bed on a weekend day) and weighted sleep duration $=5 / 7 *$ (sleep duration on a weekday) $+2 / 7 *$ (sleep duration on a weekend day). Sleep efficiency refers to the percentage of time a person sleeps in relation to the amount of time a person spends in bed and was calculated as the ratio of sleep duration and time in bed X 100.

Participants were then classified into the following three sleep categories according to their sleep duration: short $(<6$ hours), normal (6-8 hours) and long sleep duration ( $>8$ hours). Finally, in order to assess basic difficulties on sleep patterns over the previous month, participants were asked about the frequency of difficulty falling asleep, maintaining asleep and early morning awakening.

\section{Assessment of sleep disturbances}

In order to assess daytime sleepiness, insomnia, sleep quality and risk of obstructive sleep apnea (OSA), the participants filled in the following standardized scales in Greek 
version, Epworth sleepiness scale $(\mathrm{ESS})^{20}$, Athens insomnia scale (AIS) ${ }^{21}$, Pittsburgh sleep quality index (PSQI) ${ }^{22}$, and Berlin questionnaire $(\mathrm{BQ})^{23}$, respectively (Appendix).

\section{Definition of DM}

Participants were classified as diabetics if they responded positively to the questions "Have you ever been told that you are diabetic or have high blood sugar by a health professional?" or "Are you on antidiabetic medication?" 13,14 .

\section{Statistical analysis}

Statistical analysis of the data was performed using IBM Statistical Package for the Social Sciences (SPSS), version 19.0 (IBM Corp., Armonk, NY, USA). The normality of quantitative variables was tested with Kolmogorov-Smirnov test. Quantitative variables were expressed as mean \pm standard deviation (SD) and qualitative variables were expressed as absolute and relative (\%) frequencies. In particular, mean estimated time of sleep characteristics (i.e., bedtime, rise time, time in bed, and sleep duration) were expressed as HH:MM. We conducted the following analyses: (i) in the univariate analysis, the association of diabetes with subjects' characteristics, sleep characteristics and sleep disorders was assessed using the chisquare test and Student's t-test; (ii) multivariate stepwise logistic regression analysis was used to explore the independent risk factors for diabetes, controlling for all subjects' characteristics; (iii) for the evaluation of the effect of sleep duration and sleep disorders on the prevalence of diabetes, two different logistic regression models were constructed: model 1 (crude, unadjusted) and model 2 (adjusted for subjects' socio-demographic, lifestyle habits and health related characteristics). Odds ratios (OR) with their 95\% confidence intervals $(\mathrm{CI})$ were estimated as the measure of the above associations.

Receiver operating characteristic (ROC) analysis was used to provide the ability of sleep duration to classify subjects with diabetes. The area under the ROC curve (AUC), sensitivity and specificity were estimated. The optimal cutoff value of the sleep duration that differentiates diabetics from non-diabetics was derived according to Youden index. All tests were two tailed and statistical significance was considered for $p$-values $<0.05$.

\section{RESULTS}

\section{Subjects' characteristics}

91 individuals $(9.5 \%)$ were classified as diabetics. The prevalence of DM in relation to participants' socio-demographic, lifestyle and health related characteristics is summarized in Tables 1 and 2 .

\section{DM and sleep habits}

The association of DM with subjects' sleep characteristics is shown in Table 3. The weighted weekly time in bed and sleep duration were calculated and compared between the two groups; it was noted that, although diabetics used to spent $23 \mathrm{~min}$
Table 1. Prevalence of DM in relation to subjects' demographic characteristics.

\begin{tabular}{|c|c|c|c|c|}
\hline & & & DM & \\
\hline & $\begin{array}{c}\text { Total } \\
\text { sample }\end{array}$ & Frequency & $\begin{array}{l}\text { Proportion } \\
(\%)\end{array}$ & p-value \\
\hline Gender & & & & $<0.001$ \\
\hline Females & $518(54.1)$ & 28 & 5.4 & \\
\hline Males & 439 (45.9) & 63 & 14.4 & \\
\hline Age & & & & $<0.001$ \\
\hline$\leq 40$ years & $273(28.5)$ & 16 & 5.9 & \\
\hline $41-60$ years & $444(46.4)$ & 20 & 4.5 & \\
\hline$>60$ years & $240(25.1)$ & 55 & 22.9 & \\
\hline Marital status & & & & $<0.001$ \\
\hline Married & $645(67.4)$ & 68 & 10.5 & \\
\hline Single & $196(20.5)$ & 4 & 2.0 & \\
\hline Divorced & $36(3.8)$ & 0 & 0.0 & \\
\hline Widowed & $80(8.4)$ & 19 & 23.8 & \\
\hline Cultural status & & & & $<0.001$ \\
\hline Greek Christians & $632(66.1)$ & 28 & 4.4 & \\
\hline Greek Muslims & $273(28.5)$ & 51 & 18.7 & \\
\hline $\begin{array}{l}\text { Expatriated } \\
\text { Greeks }\end{array}$ & $52(5.4)$ & 12 & 23.1 & \\
\hline Place of residence & & & & $<0.001$ \\
\hline Urban & $416(43.5)$ & 16 & 3.8 & \\
\hline Rural & $541(56.5)$ & 75 & 13.9 & \\
\hline Education level & & & & $<0.001$ \\
\hline Low & $313(32.7)$ & 67 & 21.4 & \\
\hline Medium & $340(35.5)$ & 20 & 5.9 & \\
\hline High & $304(31.8)$ & 4 & 1.3 & \\
\hline Working Status & & & & 0.129 \\
\hline Employed & 872 (91.1) & 79 & 9.1 & \\
\hline Unemployed & $85(8.9)$ & 12 & 14.1 & \\
\hline $\begin{array}{l}\text { Financial status } \\
(\mathrm{n}=812)\end{array}$ & & & & $<0.001$ \\
\hline Low & $476(49.7)$ & 75 & 15.8 & \\
\hline Medium & $200(20.9)$ & 12 & 6.0 & \\
\hline High & $136(14.2)$ & 0 & 0.0 & \\
\hline
\end{tabular}

longer time in bed $(p=0.001)$, they reported a 26 min shorter sleep duration $(p=0.005)$ and lower sleep efficiency $(p<0.001)$ compared to non-diabetics. All the above relations between DM and sleep characteristics remained unchanged among females and males. In particular, females with DM used to sleep 44 min less than females without DM $(p<0.001)$ and males with DM used to sleep 27 min less than males without DM $(p<0.001)$. Among subjects with DM, all three sleep characteristics were similar between males and females (time in bed: $p=0.882$; sleep duration: $p=0.356$; sleep proportion: $p=0.171$ ).

In the sequence, according to the self-reported sleep duration, participants were categorized into three groups: short $(<6 \mathrm{~h})$, normal $(6-8 \mathrm{~h})$ and long $(>8 \mathrm{~h})$ sleep duration. The association between DM and sleep duration, which was considered as a categorical variable (Table 4), revealed that DM was significantly more frequent $(p<0.001)$ in subjects with short $(16.7 \%)$ compared to those with normal $(7.2 \%)$ and long $(8.8 \%)$ 
Table 2. Prevalence of DM in relation to subjects' lifestyle habits and health related characteristics.

\begin{tabular}{|c|c|c|c|c|}
\hline & \multirow[b]{2}{*}{ Total sample } & \multirow[b]{2}{*}{ Frequency } & $\mathbf{D M}$ & \multirow[b]{2}{*}{ p-value } \\
\hline & & & $\begin{array}{l}\text { Proportion } \\
(\%)\end{array}$ & \\
\hline Smoking ever & & & & 0.001 \\
\hline Never smoked & $369(38.6)$ & 19 & 5.1 & \\
\hline Ex-smoker & 255 (26.6) & 35 & 13.7 & \\
\hline $\begin{array}{l}\text { Current } \\
\text { smoker }\end{array}$ & $333(34.8)$ & 37 & 11.1 & \\
\hline \multicolumn{2}{|c|}{ Alcohol consumption } & & & $<0.001$ \\
\hline Never & $488(51.0)$ & 70 & 14.3 & \\
\hline $\begin{array}{l}\text { Occasionally or } \\
\text { daily }\end{array}$ & $469(49.0)$ & 21 & 4.5 & \\
\hline \multicolumn{2}{|c|}{ Coffee consumption } & & & 0.003 \\
\hline None & $84(8.8)$ & 8 & 9.5 & \\
\hline $1-2$ cups/day & $564(58.9)$ & 51 & 9.0 & \\
\hline $3-4$ cups/day & $260(27.2)$ & 20 & 7.7 & \\
\hline$>4$ cups/day & $49(5.1)$ & 12 & 24.5 & \\
\hline \multicolumn{3}{|c|}{ Caffeine consumption in the evening ( $>6$ p.m.) } & & 0.146 \\
\hline No & $415(43.4)$ & 46 & 11.1 & \\
\hline Yes & $542(56.6)$ & 45 & 8.3 & \\
\hline \multicolumn{2}{|c|}{ Number of meals } & & & 0.002 \\
\hline 1 meal & $20(2.1)$ & 0 & 0.0 & \\
\hline 2 meals & $353(36.9)$ & 20 & 5.7 & \\
\hline$>2$ meals & $584(61.0)$ & 71 & 12.2 & \\
\hline \multicolumn{2}{|c|}{ Adherence to MED diet } & & & $<0.001$ \\
\hline Low & $743(77.6)$ & 84 & 11.3 & \\
\hline High & $214(22.4)$ & 7 & 3.3 & \\
\hline \multicolumn{4}{|c|}{ Time watching TV or using a computer before bedtime } & 0.304 \\
\hline$<1$ hour & $120(12.5)$ & 8 & 6.7 & \\
\hline $1-2$ hours & $326(34.1)$ & 28 & 8.6 & \\
\hline$>2$ hours & $511(53.4)$ & 55 & 10.8 & \\
\hline \multicolumn{2}{|l|}{ Physical activity } & & & $<0.001$ \\
\hline Low & $805(84.1)$ & 91 & 11.3 & \\
\hline High & $152(15.9)$ & 0 & 0.0 & \\
\hline \multicolumn{2}{|c|}{ Nap during the day } & & & 0.008 \\
\hline No & $721(75.3)$ & 79 & 11.0 & \\
\hline Yes & $236(24.7)$ & 12 & 5.1 & \\
\hline \multicolumn{2}{|c|}{ Subjective health status } & & & $<0.001$ \\
\hline $\mathrm{Bad}$ & $220(23.0)$ & 59 & 26.8 & \\
\hline Good & $737(77.0)$ & 32 & 4.3 & \\
\hline BMI status & & & & $<0.001$ \\
\hline Normal & $328(34.3)$ & 12 & 3.7 & \\
\hline Overweight & $272(28.4)$ & 27 & 9.9 & \\
\hline Obese & $357(37.3)$ & 52 & 14.6 & \\
\hline \multicolumn{2}{|c|}{ Anxiety symptoms } & & & 0.015 \\
\hline No & $635(66.4)$ & 50 & 7.9 & \\
\hline Yes & $322(33.6)$ & 41 & 12.7 & \\
\hline \multicolumn{2}{|c|}{ Depression symptoms } & & & $<0.001$ \\
\hline No & $685(71.6)$ & 40 & 5.8 & \\
\hline Yes & $272(28.4)$ & 51 & 18.8 & \\
\hline \multicolumn{2}{|c|}{ Use of sleep medication } & & & 0.453 \\
\hline No & 891 (93.1) & 83 & 9.3 & \\
\hline Yes & $66(6.9)$ & 8 & 12.1 & \\
\hline
\end{tabular}

sleep duration. The association of DM with sleep duration had the same pattern in both genders $(p=0.033$ for females; $p=0.040$ for males). In particular, logistic regression analysis revealed that in subjects with short sleep duration there were more than 2.5-times higher odds for DM compared to subjects with normal sleep duration $(\mathrm{OR}=2.59, p<0.001)$. A 2.96 -fold $(p=0.012)$ and a 2.07 -fold $(p=0.015)$ increase in odds of DM was associated with short sleep duration in females and males, respectively.

\section{Independent effect of DM on sleep habits}

Two separate multivariate logistic regression models, controlling for the effect of all subjects' socio-demographic, lifestyle and health related characteristics, were constructed in order to assess the independent effect of sleep duration on the prevalence of DM. When sleep duration was entered in the model as a continuous variable, it remained a statistically significant independent determinant of increased odds for diabetes $(p=0.002)$; in particular, shorter sleep duration by one hour was associated with a $41 \%$-increase in the odds for DM $(\mathrm{aOR}=1.41,95 \% \mathrm{CI}=1.13-1.76)$.

When sleep duration was entered in the multivariate logistic regression model as a categorical variable, the inverse relationship between DM and sleep duration persisted even after the adjustment for all potential confounders. In particular, the odds of DM were almost 3 times higher for subjects sleeping less than 6 hours ( $\mathrm{aOR}=2.82, p<0.001$ ) compared to those with normal sleep duration; the respective odds for DM were similar in the two genders $(\mathrm{aOR}=2.51, p=0.033$ in females; $\mathrm{aOR}=2.53$, $p=0.006$ in males). Sleeping longer than 8 hours showed no significant effect on the development of DM (Table 4).

Moreover, the area under the ROC curve (AUC) showed that sleep duration has a significant ability to discriminate subjects with DM (AUC $=0.634, \quad 95 \% \quad \mathrm{CI}=0.564-0.702$, $p=0.035$ ). The optimal cut-off point of sleep duration of $5: 33$ hours, which was determined to classify subjects with DM, yielded high sensitivity of $60.4 \%$ and specificity of $77.4 \%$. Sleep duration showed significant discrimination ability in both genders, although its performance was superior among females (females: AUC $=0.729,95 \% \mathrm{CI}=0.617-0.842, p<0.001$, cut-off $\leq 6: 04$ hours, sensitivity $=85.7 \%$, specificity $=66.6 \%$; males: $\mathrm{AUC}=0.579,95 \% \mathrm{CI}=0.493-0.664, p=0.045$, cut-off $\leq 5: 38$ hours, sensitivity $=55.5 \%$, specificity $=73.5 \%$ ).

\section{DM and sleep disorders}

According to the Greek versions of ESS, AIS, PSQI and BQ the prevalence of daytime sleepiness was $8.7 \%$ ( 83 subjects), insomnia $18.0 \%$ (172 subjects), poor sleep quality $38.5 \%$ (368 subjects) and high risk of obstructive sleep apnea 36.4\% (348 subjects). The internal consistency of all four questionnaires was very high (Cronbach $\alpha$ coefficient was ranged from 0.74 to 0.88). The development of DM in relation to sleep disorders is shown in Table 5. Univariate statistical analysis showed that DM was more frequent in subjects with excessive daytime sleepiness $(20.5 \%$ vs $8.5 \%, p<0.001)$, insomnia $(14.0 \%$ vs $8.5 \%$, $p=0.028)$, poor sleep quality $(14.4 \%$ vs $6.5 \%, p<0.001)$ and high 
Table 3. Association of diabetes with sleep characteristics.

\begin{tabular}{|c|c|c|c|c|c|}
\hline & \multirow[b]{2}{*}{ Total sample } & \multicolumn{2}{|c|}{ Diabetes } & \multirow[b]{2}{*}{ Difference* } & \multirow[b]{2}{*}{ p-value } \\
\hline & & No & Yes & & \\
\hline \multicolumn{6}{|l|}{ Weekdays sleep habits } \\
\hline Bedtime & $11: 29(1: 05)$ & $11: 34(1: 05)$ & $10: 44(0: 42)$ & $-50(4.3)$ & $<0.001$ \\
\hline Rise time & $6: 53(1: 01)$ & $6: 55(1: 02)$ & $6: 34(0: 47)$ & $-21(4.0)$ & 0.002 \\
\hline Time in bed & $7: 24(1: 05)$ & $7: 21(1: 05)$ & $7: 50(0: 58)$ & $29(4.3)$ & $<0.001$ \\
\hline Sleep duration & $6: 19(1: 11)$ & $6: 20(1: 09)$ & $6: 02(1: 25)$ & $-18(4.7)$ & 0.046 \\
\hline Sleep efficiency $(\%)$ & $86(12)$ & $87(11)$ & 77 (12) & $-10(1.2)$ & $<0.001$ \\
\hline \multicolumn{6}{|l|}{ Weekends sleep habits } \\
\hline Bedtime & $11: 55(1: 19)$ & $12: 02(1: 18)$ & $10: 51(0: 43)$ & $-71(5.0)$ & $<0.001$ \\
\hline Rise time & $7: 46(1: 32)$ & $7: 52(1: 34)$ & $6: 47(0: 47)$ & $-65(5.8)$ & $<0.001$ \\
\hline Time in bed & $7: 50(1: 00)$ & $7: 50(1: 01)$ & $7: 56(0: 52)$ & $6(4.0)$ & 0.274 \\
\hline Sleep duration & $6: 45(1: 16)$ & $6: 49(1: 13)$ & $6: 05(1: 24)$ & $-44(5.0)$ & $<0.001$ \\
\hline Sleep efficiency (\%) & $86(12)$ & 87 (11) & $76(12)$ & $-11(1.2)$ & $<0.001$ \\
\hline \multicolumn{6}{|l|}{ Weekly sleep habits } \\
\hline \multicolumn{6}{|l|}{ Total sample } \\
\hline Time in bed & $7: 32(1: 00)$ & $7: 29(1: 00)$ & $7: 52(0: 56)$ & $23(4.0)$ & 0.001 \\
\hline Sleep duration & $6: 26(1: 10)$ & $6: 29(1: 08)$ & $6: 03(1: 25)$ & $-26(4.7)$ & 0.005 \\
\hline Sleep efficiency $(\%)$ & $86(12)$ & $87(11)$ & $77(12)$ & $-10(1.2)$ & $<0.001$ \\
\hline \multicolumn{6}{|l|}{ Females } \\
\hline Time in bed & $7: 36(0: 59)$ & $7: 35(1: 00)$ & $7: 54(0: 57)$ & $19(6.8)$ & 0.109 \\
\hline Sleep duration & $6: 30(1: 10)$ & $6: 32(1: 08)$ & $5: 48(1: 24)$ & $-44(7.9)$ & 0.001 \\
\hline Sleep efficiency $(\%)$ & $86(12)$ & $87(12)$ & $74(12)$ & $-13(2.2)$ & $<0.001$ \\
\hline \multicolumn{6}{|l|}{ Males } \\
\hline Time in bed & $7: 26(1: 00)$ & $7: 23(1: 00)$ & $7: 51(0: 53)$ & $28(4.7)$ & 0.001 \\
\hline Sleep duration & $6: 22(1: 10)$ & $6: 36(1: 06)$ & $6: 09(1: 25)$ & $-27(5.4)$ & 0.191 \\
\hline Sleep efficiency $(\%)$ & $86(11)$ & $87(10)$ & $78(12)$ & $-9(1.4)$ & $<0.001$ \\
\hline
\end{tabular}

*mean difference (S.E.) between subjects with and without DM, expressed as minutes (bedtime, rise time, time in bed, and sleep duration) and as percentages (sleep efficiency).

Table 4. Association of sleep duration with DM in relation to gender using logistic regression models.

\begin{tabular}{|c|c|c|c|c|c|c|}
\hline & \multirow[b]{2}{*}{ Diabetes n (\%) } & \multirow[b]{2}{*}{ p-value } & \multicolumn{2}{|c|}{ Model 1} & \multicolumn{2}{|c|}{ Model 2} \\
\hline & & & $\operatorname{cOR}(95 \% \mathrm{CI})$ & p-value & aOR $(95 \% \mathrm{CI})$ & p-value \\
\hline \multicolumn{7}{|l|}{ Total sample } \\
\hline Sleep duration & & $<0.001$ & & & & \\
\hline Short & 35 (16.7) & & $2.59(1.61-4.18)$ & $<0.001$ & $2.82(1.70-4.70)$ & $<0.001$ \\
\hline Normal & $44(7.2)$ & & Ref. & & Ref. & \\
\hline Long & $12(8.8)$ & & $1.25(0.64-2.44)$ & 0.513 & $1.27(0.65-2.50)$ & 0.488 \\
\hline \multicolumn{7}{|l|}{ Females } \\
\hline Sleep duration & & 0.033 & & & & \\
\hline Short & $10(10.9)$ & & $2.96(1.27-6.91)$ & 0.012 & $2.51(0.99-6.49)$ & 0.033 \\
\hline Normal & $14(4.0)$ & & Ref. & & Ref. & \\
\hline Long & $4(5.6)$ & & $1.43(0.46-4.47)$ & 0.540 & $1.26(0.35-4.50)$ & 0.719 \\
\hline \multicolumn{7}{|l|}{ Males } \\
\hline \multicolumn{7}{|l|}{ Sleep duration } \\
\hline Short & 25 (21.4) & 0.040 & $2.07(1.15-3.70)$ & 0.015 & $2.53(1.31-4.88)$ & 0.006 \\
\hline Normal & 30 (11.6) & & Ref. & & Ref. & \\
\hline Long & $8(12.5)$ & & $1.09(0.47-2.50)$ & 0.847 & $1.01(0.43-2.36)$ & 0.987 \\
\hline
\end{tabular}

$\mathrm{cOR}$ = crude odds ratio; aOR = Adjusted odds ratio; $\mathrm{CI}$ = confidence interval; model 1 = Crude, unadjusted; model 2 = Adjusted for socio-demographic characteristics, lifestyle habits (smoking status, alcohol consumption, daily coffee consumption, caffeine consumption in the evening, adherence to the Mediterranean diet, time watching TV or using a computer before bedtime, physical activity, nap during the day) and health related characteristics (subjective general health status, BMI, chronic disease morbidity, anxiety, depression, and use of sleep medication). 
Table 5. Association of sleep questionnaires and sleep difficulties with DM using logistic regression models.

\begin{tabular}{|c|c|c|c|c|c|c|}
\hline & & & & Model 1 & & Model 2 \\
\hline & Diabetes n (\%) & p-value & $\operatorname{cOR}(95 \% \mathrm{CI})$ & p-value & aOR $(95 \% \mathrm{CI})$ & p-value \\
\hline \multicolumn{7}{|l|}{ Sleep questionnaires } \\
\hline ESS & & $<0.001$ & & & & \\
\hline Normal day sleepiness & $74(8.5)$ & & Ref. & & Ref. & \\
\hline Excessive day sleepiness & $17(20.5)$ & & $2.79(1.55-4.99)$ & $<0.001$ & $2.09(1.13-3.89)$ & 0.019 \\
\hline AIS & & 0.028 & & & & \\
\hline Non-insomniac & $67(8.5)$ & & Ref. & & Ref. & \\
\hline Insomniac & $24(14.0)$ & & $1.74(1.06-2.86)$ & 0.028 & $1.63(0.97-2.73)$ & 0.065 \\
\hline PSQI & & $<0.001$ & & & & \\
\hline Good quality & $38(6.5)$ & & Ref. & & Ref. & \\
\hline Bad quality & $53(14.4)$ & & $2.44(1.57-3.78)$ & $<0.001$ & $2.56(1.61-4.06)$ & $<0.001$ \\
\hline BQ & & 0.012 & & & & \\
\hline Low risk & $47(7.7)$ & & Ref. & & Ref. & \\
\hline High risk & 44 (12.6) & & $1.73(1.12-2.67)$ & 0.012 & $1.53(0.95-2.47)$ & 0.080 \\
\hline \multicolumn{7}{|l|}{ Sleep difficulties } \\
\hline Delay in falling asleep & & 0.938 & & & & \\
\hline Less than once a week & $57(9.5)$ & & Ref. & & Ref. & \\
\hline At least once a week & $34(9.6)$ & & $1.02(0.65-1.59)$ & 0.938 & $1.22(0.76-1.95)$ & 0.404 \\
\hline Inability to stay asleep & & $<0.001$ & & & & \\
\hline Less than once a week & $16(4.4)$ & & Ref. & & Ref. & \\
\hline At least once a week & 75 (12.6) & & $3.12(1.79-5.44)$ & $<0.001$ & $1.25(1.24-4.08)$ & 0.007 \\
\hline Waking-up too early & & 0.004 & & & & \\
\hline Less than once a week & $40(7.2)$ & & Ref. & & Ref. & \\
\hline At least once a week & $51(12.8)$ & & $1.89(1.22-2.92)$ & 0.004 & $1.88(1.18-3.01)$ & 0.008 \\
\hline
\end{tabular}

ESS, Epworth Sleepiness Scale; AIS, Athens Insomnia Scale; PSQI, Pittsburgh Sleep Quality Index; BQ, Berlin Questionnaire; cOR, crude Odds Ratio; aOR, adjusted Odds Ratio; CI, confidence interval; model 1, crude, unadjusted; model 2, adjusted for all socio-demographic characteristics, lifestyle habits and health related characteristics.

risk for OSA $(12.6 \%$ vs $7.7 \%, p=0.012)$. In multivariate logistic regression analysis controlling for all subjects' characteristics, the odds of DM remained significantly associated with excessive daytime sleepiness $(\mathrm{aOR}=2.09, p=0.019)$ and poor sleep quality $(\mathrm{aOR}=2.56, p<0.001)$, while its relation with insomnia $(\mathrm{aOR}=1.63, p=0.065)$ and the risk for OSA $(\mathrm{aOR}=1.53$, $p=0.080)$ were of marginal statistical significance.

Regarding to the basic difficulties of sleep patterns, significant increased odds of DM were found among subjects who reported difficulties in maintaining sleep $(\mathrm{aOR}=2.25$, $p=0.007)$ and early morning awakenings $(\mathrm{aOR}=1.88, p=0.008)$, but not difficulties initiating sleep $(\mathrm{aOR}=1.22, p=0.404)$.

\section{DISCUSSION}

A cross-sectional study utilizing a population-based sample from the rural region of Thrace in northeastern Greece was conducted in order to evaluate the potential associations of adults' sleep habits and disturbances with DM in the primary care setting. It was revealed that $\mathrm{DM}$ was more prominent among minority groups. Moreover, DM was not only associated with shorter sleep duration and reduced sleep efficiency, but also with poor sleep quality.

The high evidenced prevalence of DM, i.e., 9.5\% of the sample population studied, is consistent with the International
Diabetes Federation, according to which, the median global prevalence of DM is projected from 382 million $(8.3 \%)$ in 2013 to reach 592 million (10.1\%) in $2035^{24}$. Moreover, the prevalence of DM was noted higher among Expatriated and Muslim Greeks displaying proportions of $23.1 \%$ and $18.7 \%$, respectively, against the Greek Christians group 4.4\% (Table 1). This finding supports the hypothesis that minority groups follow inconsistent, unhealthy living and feed habits. The increased prevalence of DM in minority groups has been demonstrated in several studies ${ }^{25,26}$. Furthermore, rural citizens carry the disease almost fourfold compared to inhabitants of urban areas. This finding is in agreement with education level and poverty dependences, hence highly educated people presumed to live in urban areas appear privileged hence presenting less diabetic incidents. Indeed low-income populations in Western economies are found to develop DM more frequently ${ }^{27}$. Factors such as unhealthy feeding habits, obesity and stress contribute to higher DM frequency of unprivileged populations. The latest has been attributed to the fact that individuals of low socioeconomic status present less glycemic control prioritization, personal vulnerability and lack of easy access to health care providers ${ }^{28}$.

As evidenced in Table 3, diabetics spend 23 min longer time in bed $(p=0.001)$ and report 26 min shorter sleep duration $(p=0.005)$ and lower sleep efficiency $(p<0.001)$ compared to 
non-diabetics. Implementing multivariate logistic regression analysis, reduced sleep duration by one hour was associated with a $41 \%$ increase in the risk for DM occurrence $(\mathrm{aOR}=1.41,95 \%$ $\mathrm{CI}=1.13-1.76$ ), i.e., sleep duration demonstrates a significant ability to discriminate subjects with DM. Moreover, the odds of DM were almost 3 times higher for subjects sleeping less than 6 hours $(\mathrm{aOR}=2.82, p<0.001)$ compared to those with normal sleep duration (Table 4). Our results are in keeping with a recent meta-analysis by Shan et al. (2015) ${ }^{29}$ that concluded that reduced sleep duration is associated with significantly increased risk of DM. In contrast, in our study a relationship between long sleep duration and DM incidence could not be identified ( $\mathrm{aOR}=1.27$, $p=0.488$ ). Von Ruesten et al. $(2012)^{30}$ and Lin et al. (2016) ${ }^{31}$ could also not trace a link between long sleep duration and DM.

Certain studies evaluate duration of sleep as a three and others as four level factorial making comparison analysis hard to implement. The American Academy of Sleep Medicine and Sleep Research Society and the National Sleep Foundation advocated by the recently released relevant recommendations for adult sleep duration, according to which 7 or more hours of sleep are deemed necessary to support health ${ }^{32,33}$. The American Thoracic Society also reached the consensus warning that $6 \mathrm{~h}$ or less of sleep duration is heavily associated with disease conditions, including $\mathrm{DM}^{34}$. For our study, the optimal cut-off point was set at 5:33hours, which was determined to classify subjects with DM, yielding high sensitivity of $60.4 \%$ and specificity of $77.4 \%$.

With regards to sleep quality, our multivariate logistic regression analysis revealed that DM was significantly associated with excessive daytime sleepiness ( $\mathrm{aOR}=2.09, p=0.019)$ and poor sleep quality $(\mathrm{aOR}=2.56, p<0.001)$, while its relation with insomnia $(\mathrm{aOR}=1.63, p=0.065)$ and the risk for OSA $(\mathrm{aOR}=1.53, p=0.080)$ were of marginal statistical significance (Table 5). Ogilvie and Patel (2018) $)^{35}$ also concluded that OSA, poor sleep quality and insomnia were more prevalent in diabetics. Concerning insomnia subtypes, significant risk of DM was found among subjects who reported difficulties maintaining sleep $(\mathrm{aOR}=2.25, p=0.007)$, and early morning awakening $(\mathrm{aOR}=1.88$, $p=0.008$ ), but not, difficulties initiating sleep (aOR=1.22, $p=0.404$ ). In contrast, in a recent meta-analysis, Cappuccio et al. $(2010)^{36}$ exhibited that both difficulties initiating and maintaining sleep are associated with increased risk of DM.

Concerning the pathophysiological link between sleep pathology and DM, it has been revealed that in case of T2DM sleep deprivation is related to decreased insulin sensitivity or insulin resistance ${ }^{7,37,38}$. Metabolism related hormones leptin and ghrelin secreted by the adipose tissue and stomach, might be involved in satiety signaling, hunger stimulation and implicated in DM development. Sleep laboratory studies have also shown that acute sleep deprivation decreases leptin and increases ghrelin $^{39}$ fostering DM development. Moreover, deficient sleep contributes not only to reduced insulin release after meals, thereby maintaining glucose in the bloodstream, but also increased insulin production in an attempt to lower the elevated glucose levels attributable to increased cortisol circulating in the body following sleep loss. Furthermore, elevations in epinephrine due to increased sympathetic nervous system activity inhibit insulin release and promote glycogenolysis ${ }^{5}$. In case of T1DM, data that elucidate the potential causal role of sleep duration in glycemic control and vice versa are limited. Nevertheless, it has been suggested that adults and children with T1DM exhibit altered sleep architecture and reduced sleep quality due to both behavioral and physiological aspects of diabetes and its management. Apart from that, impaired glycemic control has been linked to OSA that is more prevalent in patients with T1DM. Moreover, it has been proposed that lack of the normal decline in blood pressure during sleep may be linked to short sleep duration in people $\mathrm{T}^{\mathrm{D}} \mathrm{DM}^{40}$. Furthermore, an experimental sleep restriction study by Donga et al. (2010) ${ }^{41}$ showed that adults with T1DM who were limited to 4 hours of sleep exhibited lower glucose tolerance and insulin sensitivity compared to when they were provided the opportunity to obtain the recommended total sleep time. Finally, potential neuroinflammatory pathways linking T1DM and sleep pathology have also been implicated ${ }^{42}$.

Our analysis manifests several strengths, as it is based on data from a large representative sample of the population of the region of Thrace that provided excellent response rates to sleep quality and DM measurements. Although participation rate was not $100 \%$ our sampling scheme ensured that the sample was randomly selected and representative of the general population of this area. Limitations of this study lie in the properties of the cross-sectional study, as it is difficult to determine if there is a causal relationship between sleep pathology and DM and the recall bias of self-reported sleep duration. Nevertheless, self-report assessments of sleep have been shown to be valid measures compared with quantitative sleep assessments with actigraphy $^{43}$. Similarly, self-reported DM could interfere in the final sample and results, as the achieved DM sample might not represent the real number of the diagnosed DM population. Even so, several studies have confirmed that the use of the datum of self-reported DM is valid ${ }^{44}$ as high concordance is evident between self-reported DM and medical DM record review $^{45}$. Furthermore, due to the vast heterogeneity in the medical regimens that act through various pathophysiological pathways and taking into consideration that many patients received multiple medications from different categories it was impossible to verify any direct association between a certain regimen to sleep patterns. Finally, although the presence of well-controlled DM as indicated by normal levels of HbA1c could be associated with improved sleep quality and quantity, data on HbA1c levels are not available, thus no conclusion on this matter could be reached.

\section{CONCLUSION}

To the best of our knowledge, this is the first crosssectional study conducted in the primary care setting in Greece that not only presents strong evidence of an association between both sleep quantity and quality and DM but also depicts an increased prevalence of the latter in minority groups. These findings dictate the strong link of sleep disturbances with 
the burden of DM rendering further research on the possible interventions to improve sleep for better glucose metabolism regulation as an urgent need in this setting with special focus in minority populations.

\section{ACKNOWLEDGEMENTS}

The contributions of all of the participants, patient advisers and interviewers are gratefully acknowledged.

\section{SOURCES OF FUNDING}

This research did not receive any specific grant from funding agencies in the public, commercial, or not-for-profit sectors.

\section{CONFLICTS OF INTEREST}

The authors report no conflicts of interest.

\section{REFERENCE}

1. Carley DW, Farabi SS. Physiology of sleep. Diabetes Spectr. 2016 Feb;29(1):5-9. DOI: https://doi.org/10.2337/diaspect.29.1.5

2. Cappuccio FP, D’Elia L, Strazzullo P, Miller MA. Sleep duration and all-cause mortality: a systematic review and meta-analysis of prospective studies. Sleep. 2010 Mav;33(5):585-92. DOI: https://doi.org/10.1093/sleep/33.5.585

3. Czeisler CA. Sleep deficit: the performance killer. A conversation with Harvard Medical School Professor Charles A. Czeisler. Harv Bus Rev. 2006 Oct;84(10):53-9.

4. Barnes CM, Drake CL. Prioritizing sleep health: public health policy recommendations. Perspect Psychol Sci. 2015 Nov;10(6):733-7. DOI: https://doi.org/10.1177/1745691615598509

5. Perfect MM. Sleep-related disorders in patients with type 1 diabetes mellitus: current insights. Nat Sci Sleep. 2020;2020:101-23. DOI: https:// doi.org/10.2147/NSS.S152555

6. World Health Organization (WHO). Health topics - Diabetes [nternet]. Geneva: WHO; 2000; [access in ANO Mês dia]. Available from: https:// www.who.int/health-topics/diabetes\#tab=tab_1

7. Karthikeyan R, Spence DW, Pandi-Perumal SR. The contribution of modern 24-hour society to the development of type 2 diabetes mellitus: the role of insufficient sleep. Sleep Sci. 2019;12(3):227-31. DOI: https:// doi.org/10.5935/1984-0063.20190061

8. Resnick HE, Redline S, Shahar E, Gilpin A, Newman A, Walter R, et al. Diabetes and sleep disturbances: findings from the Sleep Heart Health Study. Diabetes Care. 2003 Mar;26(3):702-9. DOI: https://doi. org/10.2337/diacare.26.3.702

9. Mooradian AD. Central nervous system complications of diabetes mellitus-a perspective from the blood-brain barrier. Brain Res Brain Res Rev. 1997 Apr;23(3):210-8. DOI: https://doi.org/10.1016/s0165-0173(97)00003-9

10. Cox RC, Olatunji BO. A systematic review of sleep disturbance in anxiety and related disorders. J Anxiety Disord. 2016 Jan;37:104-29. DOI: https://doi.org/10.1016/j.janxdis.2015.12.001

11. Buysse DJ, Angst J, Gamma A, Ajdacic V, Eich D, Rössler W. Prevalence, course, and comorbidity of insomnia and depression in young adults. Sleep. 2008 Apr;31(4):473-80. DOI: https://doi.org/10.1093/sleep/31.4.473

12. Lu K, Zhao Y, Chen J, Hu D, Xiao H. Interactive association of sleep duration and sleep quality with the prevalence of metabolic syndrome in adult Chinese males. Exp Ther Med. 2020;19(2):841-8. DOI: https://doi. org/10.3892/etm.2019.8290

13. Tang M, Chen Y, Krewski D. Gender-related differences in the association between socioeconomic status and self-reported diabetes. Int J Epidemiol. 2003 Jun;32(3):381-5. DOI: https://doi.org/10.1093/ije/dyg075

14. Huerta JM, Tormo MJ, Egea-Caparrós JM, Ortolá-Devesa JB, Navarro C. Accuracy of self-reported diabetes, hypertension and hyperlipidemia in the adult Spanish population. DINO study findings. Rev Esp Cardiol. 2009 Feb;62(2):143-52. DOI: https://doi.org/10.1016/s1885-5857(09)71532-4

15. Serdari A, Manolis A, Tsiptsios D, Vorvolakos T, Terzoudi A, Nena E, et al. Insight into the relationship between sleep characteristics and anxiety: a cross-sectional study in indigenous and minority populations in northeastern Greece. Psychiatry Res. 2020 Oct;292:113361. DOI: https://doi.org/10.1016/j.psychres.2020.113361

16. Vorvolakos T, Leontidou E, Tsiptsios D, Mueller C, Serdari A, Terzoudi A, et al. The association between sleep pathology and depression: a cross-sectional study among adults in Greece. Psychiatry Res. 2020 Dec;294:113502. DOI: https://doi.org/10.1016/j.psychres.2020.113502
17. Panagiotakos DB, Pitsavos C, Arvaniti F, Stefanadis C. Adherence to the Mediterranean food pattern predicts the prevalence of hypertension, hypercholesterolemia, diabetes and obesity, among healthy adults; the accuracy of the MedDietScore. Prev Med. 2007 Apr;44(4):335-40. DOI: https://doi.org/10.1016/j.ypmed.2006.12.009

18. Jemos J. Beck depression inventory; validation in a Greek sample. Athens: University Medical School; 1984.

19. Samakouri M, Bouhos G, Kadoglou M, Giantzelidou A, Tsolaki K, Livaditis M. Standardization of the Greek version of Zung's Self-rating Anxiety Scale (SAS). Psychiatriki. 2012 Jul/Sep;23(3):212-20.

20. Tsara V, Serasli E, Amfilochiou A, Constantinidis T, Christaki P. Greek version of the Epworth sleepiness scale. Sleep Breath. 2004 Apr;8(2):915. DOI: https://doi.org/10.1007/s11325-004-0091-6

21. Soldatos CR, Dikeos DG, Paparrigopoulos TJ. Athens insomnia scale: validation of an instrument based on ICD-10 criteria. J Psychosom Res. 2000 Jun;48(6):555-60. DOI: https://doi.org/10.1016/s0022-3999(00)00095-7

22. Kotronoulas GC, Papadopoulou CN, Papapetrou A, Patiraki E Psychometric evaluation and feasibility of the Greek Pittsburgh sleep quality index (GR-PSQI) in patients with cancer receiving chemotherapy. Support Care Cancer. 2011;19(11):1831-40. DOI: https://doi. org/10.1007/s00520-010-1025-4

23. Bouloukaki I, Komninos ID, Mermigkis C, Micheli K, Komninou M, Moniaki V, et al. Translation and validation of Berlin questionnaire in primary health care in Greece. BMC Pulm Med. 2013 Jan;13:6. DOI https://doi.org/10.1186/1471-2466-13-6

24. Forouhi NG, Wareham NJ. Epidemiology of diabetes. Medicine (Abingdon). 2014 Dec;42(12):698-702. DOI: https://doi.org/10.1016/j. mpmed.2014.09.007

25. Chow EA, Foster H, Gonzalez V, McIver L. The disparate impact of diabetes on racial/ethnic minority populations. Clin Diabetes. 2012 Jul;30(3):130-3. DOI: https://doi.org/10.2337/diaclin.30.3.130

26. Oldroyd J, Banerjee M, Heald A, Cruickshank K. Diabetes and ethnic minorities. Postgrad Med J. 2005;81(958):486-90. DOI: https://doi. org/10.1136/pgmj.2004.029124

27. Robbins JM, Vaccarino V, Zhang H, Kasl SV. Socioeconomic status and diagnosed diabetes incidence. Diabetes Res Clin Pract. 2005 Jun;68(3):230-6.

28. Hsu CC, Lee CH, Wahlqvist ML, Huang HL, Chang HY, Chen L, et al Poverty increases type 2 diabetes incidence and inequality of care despite universal health coverage. Diabetes Care. 2012 Nov;35(11):2286-92. DOI: https://doi.org/10.2337/dc11-2052

29. Shan Z, Ma H, Xie M, Yan P, Guo Y, Bao W, et al. Sleep duration and risk of type 2 diabetes: a meta-analysis of prospective studies. Diabetes Care. 2015 Mar;38(3):529-37. DOI: https://doi.org/10.2337/dc14-2073

30. Von Ruesten A, Weikert C, Fietze I, Boeing H. Association of sleep duration with chronic diseases in the European Prospective Investigation into Cancer and Nutrition (EPIC)-Potsdam study. PLoS One. 2012 Jan;7(1):e30972. DOI: https://doi.org/10.1371/journal.pone.0030972

31. Lin CL, Tsai YH, Yeh MC. Associations between sleep duration and type 2 diabetes in Taiwanese adults: a population-based study. J Formos Med Assoc. 2016 Sep;115(9):779-85. DOI: https://doi.org/10.1016/j.jfma.2016.01.013

32. Hirshkowitz M, Whiton K, Albert SM, Alessi C, Bruni O, DonCarlos L, et al. National Sleep Foundation's updated sleep duration recommendations: final report. Sleep Health. 2015 Dec;1(4):233-43. DOI: https://doi. org/10.1016/j.sleh.2015.10.004

33. Lin CL, Tsai YH, Yeh MC. Associations between sleep duration and type 2 diabetes in Taiwanese adults: A population-based study. J Form Med Assoc. 2016 Sep;115(9):779-85. DOI: https://doi.org/10.5664/jcsm.4950

34. Mukherjee S, Patel SR, Kales SN, Ayas NT, Strohl KP, Gozal D, et al American Thoracic Society ad hoc Committee on Healthy Sleep. An Official American Thoracic Society Statement: the importance of healthy sleep. Recommendations and future priorities. Am J Respir Crit Care Med. 2015;191(12):1450-8. DOI: https://doi.org/10.1164/rccm.201504-0767ST

35. Ogilvie RP, Patel SR. The epidemiology of sleep and diabetes. Curr Diab Rep. 2018 Aug;18(10):82. DOI: https://doi.org/10.1007/s11892-018-1055-8

36. Cappuccio FP, D'Elia L, Strazzullo P, Miller MA. Quantity and quality of sleep and incidence of type 2 diabetes: a systematic review and meta-analysis. Diabetes Care. 2010 Feb;33(2):414-20. DOI: https://doi.org/10.2337/dc09-1124

37. Morselli LL, Guyon A, Spiegel K. Sleep and metabolic function. Pflugers Arch. 2012;463(1):139-60. DOI: https://doi.org/10.1007/s00424-011-1053-z

38. Anothaisintawee T, Reutrakul S, Van Cauter E, Thakkinstian A. Sleep disturbances compared to traditional risk factors for diabetes development: systematic review and meta-analysis. Sleep Med Rev. 2016 Dec;30:11-24. DOI: https://doi.org/10.1016/j.smrv.2015.10.002

39. Spiegel K, Tasali E, Penev P, Van Cauter E. Brief communication: sleep curtailment in healthy young men is associated with decreased leptin levels, elevated ghrelin levels, and increased hunger and appetite. Ann Intern Med. 2004 Dec;141(11):846-50. DOI: https://doi.org/10.7326/00034819-141-11-200412070-00008 
40. Farabi SS. Type 1 diabetes and sleep. Diabetes Spectr. 2016 Feb;29(1):103. DOI: https://doi.org/10.2337/diaspect.29.1.10

41. Donga E, Van Dijk M, Van Dijk JG, Biermasz NR, Lammers GJ, Van Kralingen $\mathrm{K}$, et al. Partial sleep restriction decreases insulin sensitivity in type 1 diabetes. Diabetes Care. 2010 Jul;33(7):1573-7. DOI: https://doi. org $/ 10.2337 / \mathrm{dc} 09-2317$

42. Zielinski MR, Systrom DM, Rose NR. Fatigue, sleep, and autoimmune and related disorders. Front Immunol. 2019 Aug;10:1827. DOI: https:// doi.org/10.3389/fimmu.2019.01827

43. Lockley SW, Skene DJ, Arendt J. Comparison between subjective and actigraphic measurement of sleep and sleep rhythms. J Sleep Res. 1999 Sep;8(3):175-83. DOI: https://doi.org/10.1046/j.1365-2869.1999.00155.x
44. Fontanelli MM, Teixeira JA, Sales CH, Castro MA, Cesar CL, Alves MC, et al. Validation of self-reported diabetes in a representative sample of São Paulo city. Rev Saúde Pública. 2017;51:20. DOI: https://doi. org/10.1590/s1518-8787.2017051006378

45. Jackson JM, DeFor TA, Crain AL, Kerby TJ, Straver LS, Lewis CE, et al. Validity of diabetes self-reports in the Women's Health Initiative. Menopause. 2014 Aug;21(8):861-8. DOI: https://doi.org/10.1097/ GME.000000000000189 
Survey questionnaire that was administered to the participants.

I. Standard socio-demographic characteristics

\section{Gender}

Age (years)

Marital status

Cultural status

Place of residence

Education level

Employment status

Financial status: mean monthly household income

during the past three years

II. Lifestyle and dietary habits

Smoking status

Alcohol consumption

Daily coffee consumption (cups/day)

Caffeine consumption in the evening ( $>6 \mathrm{pm})$

Adherence to the Mediterranean diet 1

Time watching TV or using a computer before bedtime

Physical activity 2

Nap during the day III. Health related characteristics

Subjective general health status

Body mass index

Chronic disease morbidity ${ }^{4}$

Depression symptoms ${ }^{5}$

Anxiety symptoms ${ }^{6}$

Use of sleep medication

$$
\begin{array}{cc}
\begin{array}{c}
\text { male } \\
\leq 40
\end{array} & 41-50 \\
\text { married } & \text { single }
\end{array}
$$

Greek christians female

$$
\text { 51-60 }
$$

divorced

Greek muslims
$>70$
widowed
expatriated
Greeks

high: university

high:>2000

$\begin{array}{lr}\text { ow: } \leq 1000 & \text { high: }>2000 \\ \text { Euros } & \text { Euros }\end{array}$

high school or technical colleges

current smoker

daily

occasionally

$>4$

1-2 hours

more than 2

hours

${ }^{1}$ Adherence to the Mediterranean diet was considered as an indicator of healthy diet, it was assessed by means of the dietary indicator Mediterranean Diet Score (ranged from 0 to 55) and scores $>35$ were considered as high adherence ${ }^{17}$.

${ }^{2}$ Physical activity was assessed according to self-reported weekly frequency, duration and intensity of regular exercise (running, cycling, swimming, football, basketball, tennis, volleyball) and walking. Moderate exercise for at least 3 days per week or walking for at least 5 days per week for at least 30 min per day was classified as high physical activity

${ }^{3}$ Body mass index (BMI; weight/height2 in $\mathrm{kg} / \mathrm{m}^{2}$ ) was calculated and categorized according to the World Health Organization (WHO) criteria.

${ }^{4}$ Chronic disease morbidity was defined as the self-reported preexisting health problems, such as: hypercholesterolemia, hypertension, rheumatic disease, allergy, gastrointestinal disease, cardiac disease, diabetes, pulmonary disease, cancer and neurologic disease

${ }^{5}$ Depression symptoms were assessed using the Greek version of the Beck Depression Inventory (BDI) (a 21-item self-reporting scale; cut-off point: 13 ) ${ }^{18 .}$ ${ }^{6}$ Anxiety symptoms were assessed using the Greek version of the Zung self-rating Anxiety Scale (a 20-item self-reporting scale; cut-off point: 36 ) ${ }^{19}$

\section{Assessment of sleep habits}

At what time do you normally go to bed?

$$
\text { On weekdays }
$$

On weekends

At what time do you normally get up?

On average, how many hours do you sleep per day?

Standardized scales in Greek version that were used for the assessment of sleep disturbances

Epworth Sleepiness Scale (ESS) '

$\begin{array}{cc}\begin{array}{c}\text { Normal Daytime } \\ \text { Sleepiness }\end{array} & \begin{array}{c}\text { Excessive } \\ \text { Daytime } \\ \text { Sleepiness }\end{array} \\ \text { Non-insomniac } & \text { Insomniac }\end{array}$

Pittsburgh Sleep Quality Index (PSQI ${ }^{3}$

Berlin Questionnaire (BQ) ${ }^{4}$
Good Poor sleeper sleeper

Low risk

High risk

Athens Insomnia Scale (AIS) ${ }^{2}$

Non-insomniac Insomniac ${ }^{1}$ ESS is a widespread tool for evaluating subjective excessive daytime sleepiness. It includes 8 questions pertaining to day-to-day activities. Subjects are asked to
rate the chance of dozing off or falling asleep in 8 different situations. The score of each question ranges from 0 to 3 , and their sum is the final score of the questionnaire. Higher scores indicate a higher average sleep propensity. Based on the results, patients were classified into 2 subgroups: 0 -10 Normal Daytime Sleepiness and $>10$ Excessive Daytime Sleepiness ${ }^{20}$.

${ }^{2}$ AIS is a common self-assessment measure of insomnia-related symptoms designed for quantifying sleep difficulty based on the ICD-10 criteria. It consists of eight items: the first five pertain to sleep induction, awakenings during the night, final awakening, total sleep duration, and sleep quality; while the last three refer to well-being, functioning capacity, and sleepiness during the day. A score of $>5$ on the AIS was used to establish the diagnosis of insomnia ${ }^{21}$.

${ }^{3}$ PSQI is a standard self-assessment of sleep quality over the last month. It consists of 19 questions grouped into 7 subcategories. Specifically, the seven distinct clinical subclasses of sleep difficulties are as follows: (1) Subjective sleep quality (one question), (2) Sleep latency (two questions), (3) Sleep duration (one question), (4) Sleep efficiency (three questions), (5) Sleep disorders (nine questions), (6) Use of sleep medication (one question), (7) Daytime dysfunction (two questions). These distinct subcategories are summed and produce an overall result, with a normal value of $\leq 5$. Thus, subjects are divided into good sleepers (PSQI $\leq 5)$ and poor sleepers (PSQI $>5)^{22}$.

${ }^{4}$ The Berlin Questionnaire is one of the most common tools for identifying patients with an increased risk of OSA. It consists of 10 questions grouped into 3 categories: (1) Snoring severity (questions 1-5), (2) Daytime sleepiness or fatigue (questions 6-9), (3) History of arterial hypertension or obesity (question 10). The questions also include information about sex, age, height, and weight. Individuals are at high risk of OSA if they are positively rated in at least 2 categories, and if they are scored positively in one or none of the categories, the risk is low ${ }^{23}$. 